\title{
ВОЗМОЖНОСТИ КООПЕРАЦИИ С ГЕРМАНИЕЙ ДЛЯ УКРЕПЛЕНИЯ МИГРАЦИОННОЙ БЕЗОПАСНОСТИ РФ
}

\begin{abstract}
Аннотация. В последние годы резко возросла угроза со стороны различных миграционных процессов для внутриполитической безопасности России. Это требует постоянного совершенствования государственных механизмов, инструментов и правовых норм, обеспечивающих начиональные интересы в сфере миграчии. Важная роль в этом принадлежит изучению и использованию опыта других стран, в первую очередь, Германии. В статье рассматриваются перспективы укрепления отечественной миграционной безопасности и возможности российско-германского сотрудничества в этой сфере.
\end{abstract}

Ключевые слова: Германия, Россия, миграционная безопасность, репатриация, мигрантыл, рынок труда.

В соответствии с Указом президента РФ, утверждённого 31 декабря 2015 г. № 683, национальная безопасность РФ включает в себя оборону страны и все виды безопасности, предусмотренные Конституцией и законодательством, «прежде всего государственную, общественную, информационную, экологическую, экономическую, транспортную, энергетическую безопасность, безопасность личности» ${ }^{1}$.

Среди основных элементов национальной безопасности не упомянута миграционная безопасность, которая, на наш взгляд, является её органичной частью2. Под ней эксперты понимают правовую защищённость личности, общества и государства, которые могут быть подвержены угрозам в результате въезда на территорию нашей страны, выезда из неё, пребывания и проживания на территории страны как иностранных граждан и лиц без гражданства, так и граждан России ${ }^{3}$. С институциональной точки зрения миграционная безопасность предполагает систему разработанных государством и его региональными субъектами взаимосвязанных механизмов, инструментов и правовых норм, обеспечивающих национальные интересы в сфере миграционных процессов. Эта система определяется государственной миграционной политикой ${ }^{4}$.

(C) Белов Владислав Борисович - кандидат экономических наук, заместитель директора по научной работе, руководитель Отдела страновых исследований, руководитель Центра германских исследований ИЕ РАН. Адрес: 125009, Россия, Москва, ул. Моховая, д. 11, стр. 3. E-mail: vladisbelov@yandex.ru.

DOI: http://dx.doi.org/10.15211/vestnikieran6201811

1 «Стратегия национальной безопасности Российской Федерации» // URL: http://www.kremlin.ru/acts/bank/40391/ page/2 (дата обращения: 20.10.2018 г.).

В п. 22 упомянутой Стратегии сказано: «обостряются угрозы, связанные с неконтролируемой и незаконной миграцией, торговлей людьми, наркоторговлей и другими проявлениями транснациональной организованной преступности» // Там же.

${ }^{3}$ См., например: Попов Г.Г. Миграционная безопасность России: институционально-правовой анализ // Автореф. дисс. канд. юр. наук. - Ростов-на-Дону, 2006. С. 7-8.

${ }_{4}^{4}$ Обзор подходов к определению миграционной безопасности см. также: Назаров М.В. Миграционная безопасность: понятие, сущность и принципы // Вестник Московского университета МВД России. Юридические науки. №8. 2016. C. 31-35. 
Актуальность проблемы регулирования миграционных процессов как возможная угроза миграционной безопасности и для России и для Германии в последние годы резко возросла по ряду причин:

- масштабность миграционных потоков;

- обострение конфликтов между мигрантами и местным населением;

- активизация деятельности националистических организаций;

- несоблюдение мигрантами законодательства принимающей страны и медленный процесс интеграции мигрантов в принимающее общество;

- обострение криминогенной обстановки, преступность с участием приезжих мигрантов;

• несоблюдение норм и национально-культурных традиций;

- возникновение угрозы террористических актов;

- нарастание социальной напряжённости в местах концентрации мигрантов;

- усиление нагрузки на ресурсы страны - материальное обеспечение прибывающих мигрантов ${ }^{1}$.

Активное законотворчество в РФ в отношении миграционной политики происходило ещё в 1990-е и нулевые годы. Многое было сделано. Однако по состоянию на конец 2018 г. российское государство находилось в поиске оптимальной комплексной стратегии в сфере миграции, в т.ч. сформулированных в контексте внутриполитической безопасности долгосрочных ориентиров и видения роли мигрантов в будущем развитии России. Концепция государственной миграционной политики, утверждённая в 2012 г. и нацеленная на реализацию «положительного потенциала, заложенного в миграционных процессах» ${ }^{2}$, не смогла обеспечить в последующие годы взаимосвязанность предложенных механизмов управления миграционными процессами. Не случайно отечественное миграционное законодательство неоднократно изменялось.

Во многом поэтому ему стала имманентна несистемность и внутренняя противоречивость, из которых вытекает необходимость всестороннего открытого экспертного обсуждения существующей политики адаптации и интеграции мигрантов. Требуется исключить упрощённое понимание интеграции, в т.ч. попытки возложить ответственность за интеграцию в основном на мигрантов. Нужны разработки множественных вариантов и моделей, учитывающих сложность и многообразие нынешних миграционных потоков. Они должны быть направлены на сокращение множества рисков массовой миграции в плане внутриполитической безопасности (например, этническое размежевание общества, утрата единых ценностей и норм), обеспечение прав мигрантов, противодействие их дискриминации и маргинализации, борьбу с теневой занятостью и эксплуатацией мигрантов, их социальной исключённости и незащищённости, содействие формированию толерантного отношения титульного населения и признания им роли мигрантов для отечественного народного хозяйства страны, создание атмосферы эффективного взаимодействия мигрантов и общества.

C точки зрения ряда отечественных экспертов ${ }^{3}$, необходима Государственная федеральная программа содействия адаптации и интеграции мигрантов, за реализацию и комплексное управление которой должно отвечать Единое федеральное гражданское ведомство, создан-

\footnotetext{
${ }^{1}$ Резник Г.А., Амирова Д.Р. Миграция как угроза национальной безопасности страны: масштабы и последствия // URL: http://www.rusnauka.com/45 PWMN 2016/Economics/5 219893.doc.htm (дата обрашения: 20.10.2018 г.).

${ }^{2}$ Концепция государственной миграционной политики Российской Федерации на период до 2025 года (утв. Президентом РФ от 13 июня 2012 г.) // ГАРАНТ.PУ. URL: http://www.garant.ru/products/ipo/prime/doc/70088244/ \#ixzz5TwEPArqB (дата обращения: 20.10.2018 г.).

${ }^{3}$ См., например: Ивахнюк И.В. Предложения к миграционной стратегии России до 2035 г. - М.: Центр стратегических разработок; РСМД. Сентябрь 2017 г. - 82 с.
} 
ное вне рамок нынешнего Министерства внутренних дел РФ. Важна координация его деятельности с существующей Государственной программой по оказанию содействия добровольному переселению в РФ проживающих за рубежом соотечественников. Параллельно надо ускорить работу по разработке Миграционного кодекса, в т.ч. механизма введения репатриационного статуса, что создаст предпосылки для расширения числа её потенциальных участников. Примером для разработки репатриационного инструментария может служить аналогичный статус, существующий в Германии.

Для формирования комплексной миграционной политики, направленной на усиление внутриполитической безопасности, важно существенно повысить эффективность сбора статистической информации, что позволит увеличить уровень объективности и комплексности данных о миграционных процессах, их масштабе, структуре, о демографических, профессионально-квалификационных и иных характеристиках мигрантов. Должны существовать возможности сочетания нескольких признаков для получения комплексного «профиля» мигрантов (в т.ч. данные о половозрастном составе и социально-экономических, профессиональноквалификационных характеристиках различных категорий). Это существенно повысит качество базы для мониторинга и проведения научных исследований как основы эффективного экспертно-аналитического сопровождения государственной миграционной политики. У Германии в этой сфере есть интересный опыт, который, возможно, окажется полезным для российской практики.

Необходимо продолжить совершенствовать модель привлечения иностранной рабочей силы, которая должна стать привлекательной как для российских работодателей, так и для мигрантов, а также строиться с учётом потребностей отечественного рынка труда, имеющего сегодня дефицит высококвалифицированных кадров и необходимость регионального перераспределения трудовых ресурсов. Особого внимания заслуживает механизм привлечения иностранных высококвалифицированных специалистов. Понятно, что такая модель не должна ущемлять права отечественных работников и одновре́менно обеспечивать права трудовых мигрантов. Непосредственно с этим связан вопрос о профессиональной и языковой подготовке трудовых мигрантов, нередко не отвечающей требованиям рынка. Эта проблема существует как в РФ, так и в ФРГ. Речь идёт о создании на основе существующих и новых учебных заведений системы среднего профессионального обучения нового сегмента рынка образовательных услуг, ориентированного на специфику образования для иностранных работников и учитывающего квалификационный спрос на отечественном рынке труда.

Хорошие шансы у нашей страны есть в сфере развития образовательной миграции и привлечения иностранных студентов в отечественные вузы. Здесь также есть чему поучиться у Германии.

Российскому государству (как и германскому) необходимы новые подходы к концептуальному пониманию борьбы с незаконной миграцией. Они должны включать административные, социально-экономические меры, современный инструментарий борьбы с деятельностью криминальных этнических группировок, в т.ч. выстраивающих посреднический бизнес на незаконной миграции и незаконном трудоустройстве мигрантов. Необходимы простые и прозрачные правила и процедуры использования иностранной рабочей силы, вытеснение теневых практик оформления трудовых договоров, ужесточение ответственности работодателей и государственное наступление на теневую экономику. Одновременно нужна продуманная информационно-разъяснительная кампания воспитания толерантности, направленная на борьбу с ксенофобией, соответственно, на повышение интеграционного потенциала российского общества и создание условий для борьбы с антимиграционными настроениями.

Научно-аналитический вестник ИЕ РАН, 2018, №6 
В Германии почти тридцать лет шли дискуссии о механизмах и рамочных условиях привлечения иностранной рабочей силы, в т.ч. в контексте значительной нелегальной миграции. После долгих дебатов в декабре 2018 г. правительство Большой коалиции приняло проект долгожданного закона о трудовой миграции, который должен быть утверждён бундестагом в начале 2019 г. Если это произойдёт, то он вступит в силу в 2020 г. и будет действовать до 2022 г. После подведения промежуточных итогов будущая правительственная коалиция примет решение о дальнейшей судьбе закона. Но уже сейчас внимательное изучение текста законопроекта ${ }^{1}$ представляет существенный интерес для России.

Для разработки Государственной федеральной программы содействия адаптации и интеграции мигрантов необходимо взаимодействие между государством и субъектами миграционной политики, к которым следует отнести: экспертное сообщество, бизнес (ассоциации работодателей, использующих иностранную рабочую силу, частные агентства занятости и т.д.), неправительственные организации (правозащитные организации, информационно-консультационные службы, профсоюзы, объединения мигрантов и т.д.), диаспоры, средства массовой информации. Целесообразно в ближайшее время активизировать неформальный диалог отечественных и иностранных (в т.ч. немецких) заинтересованных экспертов, представителей правительств, бизнеса, институтов гражданского общества ${ }^{2}$. Для этого имеет смысл организовать постоянную дискуссионную площадку, ориентированную на совершенствование механизмов управления миграцией и разработку перспектив миграционного сотрудничества, на обмен информацией, идеями и положительным опытом в области международной миграции. Предметом обсуждения должна стать идентификация общих интересов и проблем России и Германии в таких областях, как вклад миграции в развитие их экономик, развитие рынков труда, обеспечение прав мигрантов, создание миграционной инфраструктуры, борьба с незаконной миграцией ${ }^{3}$.

Успешная реализация современной комплексной миграционной стратегии возможна только при тесной взаимосвязи задач, стоящих перед миграционной политикой, с социальноэкономическими задачами, государственной политикой в области занятости, образования, демографической и внешней политикой. Повысить уровень внутриполитической безопасности России способно взаимодействие различных институтов и ведомств и увязка миграционной стратегии с другими стратегическими задачами и целями развития нашей страны.

В заключение отметим возможности и перспективы кооперации между Российской Федерацией и Германией в области миграционной политики:

•полезным представляется использование немецкого опыта для разработки российского Миграционного кодекса;

\footnotetext{
${ }^{1}$ Entwurf eines Fachkräfteeinwanderungsgesetzes. Gesetzentwurf der Bundesregierung // URL: https://www.bmi.bund. de/SharedDocs/gesetzgebungsverfahren/DE/Downloads/kabinettsfassung/fachraefteeinwanderungsgesetz-kabinettsfas sung.pdf?_blob=publicationFile\& $\mathrm{v}=5$.

${ }_{2}^{2}$ С. например, российско-германскую монографию: Трудовая миграция и политика интеграции мигрантов в Германии и России: Коллективная монография / Редактор и составитель М. С. Розанова. Перевод с английского языка М.С. Розановой и А.Б. Лесохина. - СПб.: Центр гражданских, социальных, научных и культурных инициатив «СТРАТЕГИЯ»; Скифия-принт, 2016. - 192 с. Данная публикация подготовлена по материалам докладов, с которыми выступили эксперты международной конференци-10 апреля 2015 г. в Санкт-Петербургском государственном университете.

3 Председатель Комиссии по миграционной политике и адаптации мигрантов Совета по делам национальностей при правительстве Москвы Александр Калинин в качестве примера взаимного интереса германских и российских специалистов по миграции приводит разработанную в столице памятку для мигрантов, в которой через картинки в виде игры доходчиво объясняются существующие правила. Кроме того, существует аудио-версия для тех, кто не умеет читать русские тексты. После выхода памятки в 2017 г. в Москву приезжали специалисты из Германии, для того чтобы перенять тот опыт, который есть у России // URL: https://ru.sputnik-tj.com/radio/2017 1217/1024184625/kalinin-potok-migrantov-samoye-strashnoye-eto-migratsionnaya-bomba.html (дата обращения:
} 20.10.2018 г.). 
- важен опыт немецких ведомств по миграционному менеджменту, в т.ч. опыт Федерального Министерства внутренних дел, по вопросам строительства и родины - как на федеральном, так и региональном уровне, включая разработанный его сотрудниками и принятый правительством в июне 2018 г. «Генеральный план по миграции» ${ }^{1}$;

- весьма интересны для России дополнения в 2016 г. в немецкий Закон об интеграции, согласно которым реализуется план «Содействовать и требовать» ${ }^{2}$, а также принятый федеральным правительством в декабре 2018 г. законопроект о трудовой миграции ${ }^{3}-$ на основе изучения немецкой практики возможна разработка рекомендаций для будущей Государственной федеральной программы содействия адаптации и интеграции мигрантов;

- эффективным представляется обучение российских чиновников современному немецкому миграционному менеджменту, а также организация взаимных стажировок государственных служащих, отвечающих за вопросы миграции;

- государственная программа по оказанию содействия добровольному переселению в Российскую Федерацию соотечественников должна учитывать опыт Германии в сфере репатриации;

- нужен обмен опытом силовых ведомств и структур обоих государств по борьбе с криминальными группировками, организующих бизнес на нелегальной миграции, в т.ч. в сфере теневой экономики;

- вызывает интерес анализ опыта реализации исполнительного протокола между правительствами РФ и ФРГ о порядке реализации Соглашения между Российской Федерацией и Европейским сообществом о реадмиссии от 25 мая 2006 г., а также его публичное обсуждение;

- желательна кооперация в сфере составления миграционной статистики (методики сбора и получения адекватных данных, общие (международно-признанные) критерии, мониторинг и пр.);

- важным представляется обмен опытом в сфере трудовой миграции и иммиграции как высококвалифицированной, так и низкоквалифицированной, а также в области образовательных миграционных процессов; в этом контексте имеет смысл обсуждения плюсов и минусов немецкой политики по повышению привлекательности хозяйственно-политических пространств (штандортов);

- необходима организация обмена лучшими практиками в области законодательства, нацеленного на противодействие терроризму, незаконной миграции и другим угрозам безопасности граждан России и Германии как на уровне Государственной Думы РФ, Совета Федерации РФ и Бундестага, Бундесрата, так и на уровне региональных и земельных парламентов наших стран. Среди прочего их можно использовать в рамках информационно-разъяснительной кампании воспитания толерантности;

- имеет смысл подумать о создании Российско-Германского Миграционного Форума, который мог бы объединить уже существующие различные дискуссионные площадки, как, например, подгруппа Петербургского диалога «Migration task force» и Экспертный совет Института лингвоцивилизационных и миграционных процессов (ИЛМП).

\footnotetext{
${ }^{1}$ Masterplan Migration. Maßnahmen zur Ordnung, Steuerung und Begrenzung der Zuwanderung» // URL: https://www. bmi.bund.de/SharedDocs/downloads/DE/veroeffentlichungen/themen/migration/masterplan-migration.pdf?_blob= publicationFile\& $\mathrm{v}=5$.

«Fördern und fordern». URL: https://www.bmi.bund.de/SharedDocs/kurzmeldungen/DE/2017/04/integrationsmassnah men-bundesregierung.html/

${ }^{3}$ Entwurf eines Fachkräfteeinwanderungsgesetzes. Gesetzentwurf der Bundesregierung // URL: https://www.bmi.bund. de/SharedDocs/gesetzgebungsverfahren/DE/Downloads/kabinettsfassung/fachraefteeinwanderungsgesetz-kabinettsfas sung.pdf?__blob=publicationFile\&v=5.
} 


\section{Список литературы}

Ивахнюк И.В. Предложения к миграционной стратегии России до 2035 г. - М.: Центр стратегических разработок; РСМД. Сентябрь 2017 г. - 82 с.

Концепция государственной миграционной политики Российской Федерации на период до 2025 года (утв. Президентом РФ от 13 июня 2012 г.) // ГАРАНТ.PУ. URL: http://www. garant.ru/products/ipo/prime/doc/70088244/\#ixzz5TwEPArqB (дата обращения: 20.10.2018 г.)

Назаров М.В. Миграционная безопасность: понятие, сущность и принципы // Вестник Московского университета МВД России. Юридические науки. № 8. 2016. С. 31-35.

Попов Г.Г. Миграционная безопасность России: институционально-правовой анализ // Автореф. дисс. канд. юр. наук. - Ростов-на-Дону, 2006. С. 7-8.

Резник Г.А., Амирова Д.Р. Миграция как угроза национальной безопасности страны: масштабы и последствия // URL: http://www.rusnauka.com/45_PWMN_2016/Economics/5_219893. doc.htm (дата обращения: 20.10.2018 г.).

Стратегия национальной безопасности Российской Федерации // URL: http://www.kremlin.ru/acts/bank/40391/page/2 (дата обращения: 20.10.2018 г.).

Трудовая миграция и политика интеграции мигрантов в Германии и России: Коллективная монография / Редактор и составитель М.С. Розанова. Перевод с английского языка М.С. Розановой и А.Б. Лесохина. - СПб.: Центр гражданских, социальных, научных и культурных инициатив «СТРАТЕГИЯ»; Скифия-принт, 2016. - 192 с.

\section{References}

Entwurf eines Fachkräfteeinwanderungsgesetzes. Gesetzentwurf der Bundesregierung // URL: https://www.bmi.bund.de/SharedDocs/gesetzgebungsverfahren/DE/Downloads/kabinettsfassung/fac hraefteeinwanderungsgesetz-kabinettsfassung.pdf?_blob=publicationFile\&v=5.

Ivakhnyuk I.V. Predlozheniya k migratsionnoy strategii Rossii do 2035 g. - M.: Tsentr strategicheskikh razrabotok; RSMD. Sentyabr 2017 g. - 82 s. Trudovaya migratsiya i politika integratsii migrantov v Germanii i Rossii: Kollektivnaya monografiya / Redaktor i sostavitel' M.S. Rozanova. Perevod s angliyskogo yazyka M.S. Rozanovoy i A.B. Lesokhina. - SPb.: Tsentr grazhdanskikh, sotsial'nykh, nauchnykh i kul'turnykh initsiativ «STRATEGIYA»; Skifiya-print, 2016. - $192 \mathrm{~s}$.

Kontseptsiya gosudarstvennoy migratsionnoy politiki Rossiyskoy Federatsii na period do 2025 goda (utv. Prezidentom RF ot 13 iyunya 2012 g.) // GARANT.RU: http://www.garant.ru/ products/ipo/prime/doc/70088244/\#ixzz5TwEPArqB/

Masterplan Migration. Maßnahmen zur Ordnung, Steuerung und Begrenzung der Zuwanderung» // URL: https://www.bmi.bund.de/SharedDocs/downloads/DE/veroeffentlichungen/themen/ migration/masterplan-migration.pdf?_blob=publicationFile\&v=5).

Nazarov M.V. Migratsionnaya bezopasnost': ponyatiye, sushchnost' i printsipy // Vestnik Moskovskogo universiteta MVD Rossii. Yuridicheskiye nauki. №8. 2016. S. 31-35.

Popov G.G. Migratsionnaya bezopasnost' Rossii: institutsional'no-pravovoy analiz // Avtoref. diss. kand. yur. nauk. - Rostov-na-Donu, 2006. S. 7-8.

Reznik G.A., Amirova D.R. Migratsiya kak ugroza natsional'noy bezopasnosti strany: $\begin{array}{lc}\text { masshtaby i } & \text { posledstviya } \\ \text { http://www rusnauka.com/45 PWMN 2016/Economics/5 219893.doc.htm. }\end{array}$

Strategiya natsional'noy bezopasnosti Rossiyskoy Federatsii // URL: http://www.kremlin.ru/acts/bank/40391/page/2/ 


\section{Opportunities for cooperation with Germany to strengthen the migration security of the Russian Federation}

Author. Vladislav Belov, Candidate of Sciences (Economics), Deputy Director of IE RAS, Head of Department for Countries Stidies, Head of Center for German Studies, Institute of Europe, Russian Academy of Sciences. Address: 11-3, Mohovaya str., Moscow, Russia, 125009. E-mail: vladisbelov@yandex.ru.

Abstract. The threat from various migration processes for the internal political security of Russia has sharply increased. This requires constant improvement of state mechanisms, instruments and legal norms that ensure national interests in the field of migration. An important role in this belongs to the study and use of the experience of other countries, primarily Germany. The article discusses the prospects for strengthening domestic migration security and the possibilities for Russian-German cooperation in this field.

Key words: Germany, Russia, migration security, repatriation, migrants, labor market.

DOI: http://dx.doi.org/10.15211/vestnikieran6201811 